\title{
A changing landscape of road traffic liability in China
}

Citation for published version (APA):

Yan, Y. (2018). A changing landscape of road traffic liability in China: A view from law and economics. [Doctoral Thesis, Maastricht University]. Datawyse / Universitaire Pers Maastricht. https://doi.org/10.26481/dis.20180914yy

Document status and date:

Published: 01/01/2018

DOI:

10.26481/dis.20180914yy

Document Version:

Publisher's PDF, also known as Version of record

\section{Please check the document version of this publication:}

- A submitted manuscript is the version of the article upon submission and before peer-review. There can be important differences between the submitted version and the official published version of record.

People interested in the research are advised to contact the author for the final version of the publication, or visit the DOI to the publisher's website.

- The final author version and the galley proof are versions of the publication after peer review.

- The final published version features the final layout of the paper including the volume, issue and page numbers.

Link to publication

\footnotetext{
General rights rights.

- You may freely distribute the URL identifying the publication in the public portal. please follow below link for the End User Agreement:

www.umlib.nl/taverne-license

Take down policy

If you believe that this document breaches copyright please contact us at:

repository@maastrichtuniversity.nl

providing details and we will investigate your claim.
}

Copyright and moral rights for the publications made accessible in the public portal are retained by the authors and/or other copyright owners and it is a condition of accessing publications that users recognise and abide by the legal requirements associated with these

- Users may download and print one copy of any publication from the public portal for the purpose of private study or research.

- You may not further distribute the material or use it for any profit-making activity or commercial gain

If the publication is distributed under the terms of Article $25 \mathrm{fa}$ of the Dutch Copyright Act, indicated by the "Taverne" license above, 


\section{Chapter 7 \\ Summary, Policy Recommendations and Future Developments}

\section{Answers to Research Questions and Summary of Main Findings}

As set out in the introduction of this dissertation, the main aim of this research is to analyze the Chinese traffic liability system from a particular angle, the economic analysis of law. Even though the main focus is the traffic liability system, other legal instruments and their interaction with traffic liability have also been examined. Furthermore, in the introduction of this book, five research questions are posted. In this chapter, the answers to these questions are summarized, based on the discussions in the previous chapters.

\subsection{Answers to Research Question 1 and Main Findings from Chapters 1 and 2}

Question 1: What legal instruments exist in China concerning both the goals of prevention of road traffic accidents and victim compensation? How did these legal instruments change over time and what are the reasons behind these changes?

These questions have been discussed in Chapters 1 and 2. This research question actually includes three sub-questions. The first one concerning what kinds of legal instruments there are to achieve both the goal of traffic accident prevention and of victim compensation. The latter two sub-questions are related to the historical development of these legal instruments. More specifically, how these frameworks evolved and the reasons behind this evolution are identified. Sub-question one is addressed in subsection 1.1.1, while the latter two subquestions are addressed in subsection 1.1.2.

\subsubsection{Legal Instruments for Road Traffic Accident Prevention and Victim Compensation}

Traffic safety regulation and the traffic liability system are jointly used in China to prevent traffic collisions on the road. More specially, traffic safety regulation is the primary instrument to control traffic accident risks. In cases where there are regulatory gaps and where the deterrent effect of traffic safety regulation fails, the traffic liability system plays a role in supplementing traffic safety regulation.

With respect to the goal of victim compensation, a comprehensive framework has been established in China to compensate victims of road traffic accidents. Liability insurance, including both compulsory and optional insurances, social security schemes, first-party insurance, together with the traffic liability system are all adopted to guarantee full compensation. However, the role played by the above-mentioned instruments varies significantly in practice. More specifically, the goal of compensation is mainly achieved via compulsory liability insurance and the traffic liability system, whereas the role played by other instruments is extremely limited. 


\subsubsection{Historical Development of the Instruments and Reasons Behind Changes}

The development of the Chinese road traffic liability system can be divided into two phases. In the first phase (1949-1986), the road traffic liability system had a hybrid character, mixing concepts and standards in tort law and administrative law. Moreover, in this phase, most traffic accident compensation disputes were resolved out of the court by the public security authorities. Compensation was often paid by the traffic offenders' work units via the social welfare system, but the amount of compensation awarded was extremely low. All of this has radically changed in the second phase of development (1987-now). The traffic liability system started to turn into a tort system. Since 1992, the amount of compensation awarded has largely increased. And most importantly, the compulsory liability insurance scheme was introduced in May 2004 nationally. The following sub-sections summarize the specific changes within the above-mentioned two phases.

Reforms of the Basis of Liability. In the first phase of development, provisions on road traffic liability sporadically appeared in administrative regulations (which were issued by the public security bureau) and in local legislations (which were promulgated by the local government). Within these regulations and local legislations, there may be a provision, a part of which contains issues relating to traffic liability, while the other parts of the same provision explain how to punish traffic offenders. ${ }^{1}$ In this sense, there was no separate law on tort in the first phase of development. Provisions on road traffic liability were dispersed among administrative regulatory provisions and existed as an auxiliary of administrative regulation. Because of this legislative style, during the period between 1949 and 1986, the determination of road traffic liability took place on the basis of the administrative law. For example, it was the public security authorities instead of the judge who determined liability when a traffic accident happened. Furthermore, these authorities also tended to divide traffic liability into six categories based on the offender's relative contribution to the accident, as well as other administrative law concerns. ${ }^{2}$

In the second phase of development, the road traffic liability system began to evolve into a tort system. The basis of traffic liability changed a lot during this phase. To be more specific, before 1987, a fault-based liability system was applied to traffic accidents that happened on the road. However, from January 1987 to December 1991, the Chinese legislators began to realize that driving activities involve a high degree of risk and may result in serious harm. As a result, during that period, drivers of "high-speed tools of transport" (gaosu yunshu gongju) were held strictly liable for the accident that they caused (see article 123 of the GPCL). ${ }^{3}$ However, since this article did not specify whether strict liability should also be applied for those accidents that were caused by low-speed vehicles or pedestrians, this article was interpreted differently across different local governments. Due to the inconsistencies, a special statute, particularly designed to handle road traffic accident related issues, was published by the State Council in September 1991. According to this special statute, a faultbased liability should be applied to all types of road traffic accidents (see articles 17, 18, and 19 of the 1991 Regulation). Apparently, these articles violated article 123 of the GPCL, which

\footnotetext{
${ }^{1}$ See for example article 80 of the 1951 Interim Regulation, which was discussed in section 2.1 of Chapter 1.

${ }^{2}$ See for example article 9 of the 1983 Guangdong Interim Measures, which was discussed in section 2.3 of Chapter 1.

${ }^{3}$ See supra. section 2,1 of Chapter 2.
} 
was promulgated by the NPC of China and is placed at a higher level than the Rule for Handling RTA. Aware of problems with the Rule for Handling RTA, the Standing Committee of the NPC enacted another special statute, the RTSL. Article 76 of the RTSL requires that strict liability should be applied to traffic accident cases that involve motorized vehicles, whereas fault liability should be applied to other cases. Even though this article is in line with article 123 of the GPCL, it received much criticism after its promulgation. Most of the opposing opinions were targeted at the imposition of strict liability, according to which such a rule tends to overly protect the non-motor vehicle parties. Due to the strong opposition from the public, article 76 of the RTSL was amended in December 2007. Under the modified article 76, presumed fault liability should be applied for traffic accidents that involve motor vehicles, whereas for other types of traffic accidents, the fault-based liability should still be applied.

Reform of the Defences. The contributory negligence defence has been well recognized and widely applied in China since the year when the 1951 Interim Regulation was promulgated. With such a defence, the tortfeasor's liability to pay damages would be eliminated considering the victim's fault. ${ }^{4}$ Moreover, this defence cannot be successfully invoked if the tortfeasor's conduct amounts to intentional wrongdoing. However, since 1992, a very important limitation has been imposed on the contributory negligence defence in China. ${ }^{5}$ This limitation is called the " $10 \%$ rule", under which the tortfeasor must still bear up to $10 \%$ of the damages even if (s)he is not at fault. Nevertheless, the "10\% rule" cannot be applied in cases where the victim deliberately or intentionally causes the accident.

Reform of the Determination of fault and causation. Within both the first and the second phase of development, fault and causation needed to be proved in the first place to establish liability. The exceptions are situations where the rule of strict liability is applied. In the first phase of development, fault and causation were determined by the public security department instead of by the court. Moreover, a driver was often considered liable for the accident as long as (s)he has violated certain traffic safety regulations and suffered damage. In the second phase, even though the determination of fault and causation was still first conducted by the police security officers, their decisions will only be treated as evidence in trial and can be questioned by the court. Furthermore, at this stage, the unlawful conduct of the injurer is not sufficient to establish liability; other issues, including fault (if the rule of fault liability is applied), causation, and damage, also need to be proved.

Reform of the Quantum Rules. In the first phase of development, rules regarding the award of traffic damages were scattered in judicial replies (issued by the SPC), ${ }^{6}$ administrative regulations (enacted by the Ministries in the State Council), ${ }^{7}$ and local legislations. ${ }^{8}$ Usually, it was the traffic offender's work unit rather than the offender who compensated the victim. This is because, back then, almost every individual belonged to a certain organization and most motor vehicles were publicly owned. As a result, in most cases, the traffic offender's

\footnotetext{
${ }^{4}$ See article 84 of the 1951 Interim Regulation, article 131 of the GPCL and article 76 of the Road Traffic Accident Law.

${ }^{5}$ The "10\% rule" has been abolished by the RTSL during the period from May 2004 to November 2007, but it has been re-introduced by the amendment of the RTSL in December 2007. See supra. section 2.2.1, 2.3 and 2.4 of Chapter 2.

${ }^{6}$ See supra. 3.1, 3.2 of Chapter 1.

${ }^{7}$ See supra. section 3.2.1, 3.2.2 and 3.2.3 Chapter 1.

${ }^{8}$ See supra. section 3.3 of Chapter 1.
} 
employer was held vicariously liable to pay compensation, and the employer was likely to pay the compensation through a labour insurance fund in some regions. ${ }^{9}$ Moreover, when the victim was a government or military employee and the victim was dead, the victim's family members were entitled to claim an extra amount of compensation from the Ministry of Civil Affairs. ${ }^{10}$ The payment would be provided in a lump sum, but the amount was very limited.

However, in other cases where the traffic offenders did not belong to any work units, compensation would often be paid out of the offenders' own pockets. This is because the liability insurance scheme for motor vehicles has not been developed in China until the early 1980s. ${ }^{11}$ Therefore, during the first phase of development, only very few drivers had liability insurance coverage. In other words, most traffic offenders were self-insured. However, since the first phase of development was governed by the idea of "limited compensation" (buchang) rather than "full compensation" (peichang), the amount of compensation awarded was very low in the case of death (e.g. no more than the victim's annual salary). ${ }^{12}$ Given this fact, even if liability insurance and other insurance schemes were not available to the traffic offenders during 1949 and 1986, the offenders could still afford to pay the compensation.

Since January 1987, issues relating to how to compensate traffic victims were integrated and the amount of compensation awarded has been largely increased. Now, these issues are regulated by four laws, the GPCL (article 119), the TLL (article 16-25) and two judicial interpretations which are enacted by the SPC. The former two laws generally list which kinds of losses are recoverable. In terms of how to calculate the damages, the court needs to further refer to the latter two judicial interpretations. In the light of those two interpretations, future damages due to disability and death, as well as the living expenses for the dependent are measured in a standardized way. For example, death compensation equals the average consumption expenditure or living cost in the place where the court is located multiplied by a fixed period (usually no more than 20 years). ${ }^{13}$ The victim's personal income will only be considered when computing their loss of income. Moreover, unlike the first phase of development when the award for pain and suffering was totally denied, such an award has been allowed ever since January 1987 when the GPCL was promulgated.

Evolution of the Traffic Safety Regulation System. In China, traffic safety has been heavily regulated by the government in both phases of development. In May 2004, the RTSL, a national law on traffic safety entered into force and is still effective now. This law, promulgated by the Standing Committee of the NPC, establishes a framework for road safety. Moreover, the responsibility for enforcement is conferred to the traffic management department of the Ministry of Public Security, whereas the responsibility for drafting local laws and deciding how to implement the RTSL is delegated to the local government. According to the information collected by the Chinalawinfo, the local governments across China have enacted 148 local legislations in order to implement the RTSL within their own regions.

\footnotetext{
${ }^{9}$ The labour insurance program has not been launched on a national level and was only introduced in a few regions. See supra. section 3.2.1 of Chapter 1.

${ }^{10}$ See supra. section 3.2.3 of Chapter 1.

${ }^{11}$ Since the early 1980s, only a few provinces decided to launch liability insurance scheme. But at that time, the liability insurance scheme was merely applied to tractors and a certain type of motor vehicles that were used by joint-group farmers. See supra. section 5 of Chapter 1.

${ }^{12}$ See supra. section 3.1 of Chapter 1.

${ }^{13}$ See supra. section 3.2 and 3.3 of Chapter 2.
} 
In addition to traffic safety regulation, there is another type of regulation, the driver licensing system, which provides flexible regulatory control of traffic safety. In practice, motor vehicle drivers should obtain a licence before they can drive on the road; otherwise they will be subject to administrative punishments and/or criminal penalties. ${ }^{14}$ The driver licensing system was introduced in China in 1949. In March 2000, a demerit points system was further added to drivers' licences, whereby drivers who commit specific traffic offences were given demerit points. The current legal basis for the administration of the driving licensing system is the Provisions on the Application for and Use of Motor Vehicle Driving Licences, enacted by the Ministry of Public Security in August 2012 and came into effect in January 2013.

Evolution of the Motor Vehicle Liability Insurance Scheme. Between 1949 and 1980, under the influence of the Soviet Union, liability insurance was wiped out of China, because of the fear that it might interfere with the deterrent effect of liability. ${ }^{15}$ From July 1981 to April 2004, liability insurance started to develop in China. During that period, only a limited group of vehicles (i.e. motorcycles, taxi, and other commercial motor vehicles) was mandated to purchase liability insurance. From January 1998, a few economically developed regions, such as Beijing and Guangdong, started to require all types of motor vehicles to carry liability insurance, without which they could not apply for a licence plate to run on the road. Nevertheless, such a rule only worked within that particular region. A national-level compulsory motor vehicle liability insurance (CVLI) scheme was not introduced in China until June 2003. However, the duty to insure was poorly enforced between June 2003 and July 2006, mainly because the statutory duty that ensures the enforcement of the obligation to insure was not well-established during that period. This unsatisfactory situation was changed in the second half of 2006, when a specific regulation on CVLI came into force. Therefore, it can be concluded that the CVLI scheme in China is very "young" and has not been fully enforced until recently.

The current legal basis for CVLI is article 17, 76 of the RTSL and the Regulation on CVLI. When a traffic accident occurs and the liable person is insured under the CVLI, the victim's loss will first be covered by the CVLI insurer up to the limits of coverage. Beyond those limits, tort liability rules apply and the loss is assigned among the parties involved according to their relative degree of fault. Moreover, only the insured driver rather than the third-party victim is entitled to claim the payment from the CVLI insurer. However, the third-party victim may still have the chance to obtain payment from the CVLI insurer directly, if the insurer voluntarily chooses to do so. Lastly, it should be noted that the Chinese CVLI scheme has a weak link with tort liability. Even allowing for this fact, the CVLI in China cannot be classified as "no-fault insurance", as it does not pay immediately whenever an accident or injury happens.

Evolution of Other Insurance Schemes. In addition to the CVLI and tort damages, victims of traffic accidents may also receive compensation from other sources, such as optional motor vehicle liability insurance (OVLI), first-party insurance, and some social insurance plans.

\footnotetext{
${ }^{14}$ An unlicensed driver will be subject to criminal penalties if ( $\mathrm{s}$ ) he causes large property loss (more than 300,000 yuan), serious injuries or death. See article 133 of the Criminal Law.

${ }^{15}$ See supra. section 5 of Chapter 1.
} 
The development of the OVLI and first-party insurance can be traced back to the 1950s in China. However, those insurance products were removed from the market shortly afterwards in 1959, due to the influence of the Soviet Union and the cultural revolution. Those insurance products were not re-introduced into China until the 1980s. However, at the beginning only one state-owned insurance company was authorized to sell those insurances. From 1985, the monopoly in the insurance market was broken up and since then the OVLI and first-party (victim) insurance began to develop very fast. In June 1995, the Insurance Law, the first national legislation for regulating the insurance contracts and the administration of the insurance industry, finally came out. This Law has been working as the legal basis for the OVLI and first-party insurance until now. Recent data shows that the number of people covered by the OVLI and first-party (victim) insurance increases year by year, but still, the number is deemed to be very small.

It is worth pointing out that China has a long tradition of providing compensation to traffic victims via social security schemes, as described in Chapter 1 . In the early stage (1949-1986), social insurance even functioned as the primary source of monetary aid to traffic victims. Even though this situation has been changed a lot in the later stage (1986-now), the aim of social security has stayed the same over time. Social security schemes were only intended to provide a minimum level of compensation for particular groups. This means that in order to qualify for social security benefits, a person has to meet certain conditions, required by the Social Insurance Law and the Interim Measures for Social Assistance (i.e. disability or unemployment). The available data shows that nine out of ten persons in China are insured under the Basic Medical Insurance, and four out of five people are protected under the Basic Pension Insurance.

In the cases of traffic accidents, the losses suffered by the injured persons can be covered by the Work-Related Injury Insurance (WII), provided that the accidents occurred in the course of work. Also, the injured persons' losses may be covered by the Assistance Fund for Temporary Hardship, if they are extremely poor or suffer serious temporary financial issues. Additionally, certain medical expenses may be covered by the Basic Medical Insurance (BMI) or the Medical Assistance Scheme (MAS) for the poor, if those expenses fall within the preapproved government's catalogue. Lastly, loss of earning capacity due to serious disability, as well as funeral expenses may be covered under the Basic Pension Insurance (BPI) up to a limited amount (less than $25 \%$ of the annual income or two months' salary).

In China, the first-party insurance and social security schemes that are described above are parallel to the tort system. However, whether the benefits received by tort victims under these schemes should be deducted from the damages is a question that cannot be answered generally. Firstly, the personal injury coverages paid by the first-party insurance are not deductible, whereas in contrast, the property damage coverages paid by such insurance should be deducted. ${ }^{16}$ Secondly, as a general rule, social security benefits, such as payments from the BMI and the WII, should not be deducted from the tort damages. However, as an exception, expenses that should be paid by a third-party (i.e. a tortfeasor) should, in principle, not be covered by certain social insurance schemes (i.e. the WII and the BMI). ${ }^{17}$ However, if the third party refuses to pay or cannot be identified, only the medical expenses can be pre-

\footnotetext{
${ }^{16}$ See supra. section 4.2.4 and 5.3.4 of Chapter 2.

${ }^{17}$ See articles 30 and 42 of the Social Insurance Law.
} 
paid by the WII or BMI carriers, who can then bring a recourse action against the third party. In other words, in cases where the accident is caused by a third party, double compensation from both tort and social security is normally not allowed in China. Hence, to obtain compensation, the victim has to file a claim against the third-party tortfeasor. The victim is entitled to claim against the social security carriers directly, only if the third-party tortfeasor refuses to pay or if the third-party tortfeasor cannot be found. Apparently, this rule is problematic, as it creates incentives for the victim to keep silent or even lie about who caused the accident. Moreover, when the accident is not caused by the third-party tortfeasor, the victim seems to be better-off, because (s)he can be indemnified by the social security schemes directly.

\subsection{Answers to Research Question 2 and Main Findings from Chapters 1 and 2}

Question 2: How are the above-mentioned instruments enforced and are they actually operated in practice as designed? If not, what are the problems and why do these problems arise?

This question has been discussed in Chapters 1 and 2 and it can further be divided into several sub-questions. Firstly, are the above-mentioned traffic accident prevention and compensation instruments strongly enforced in practice? Secondly, are these instruments operated in accord with the designed aims? If the answers to both sub-questions are negative, then what are the problems and why do these problems arise? The first sub-question is answered in subsection 1.2.1, while the latter is discussed in subsection 1.2.2.

\subsubsection{Enforcement of Traffic Accident Prevention and Compensation Instruments in China}

Traffic safety has been closely regulated in China. Theoretically, if this type of regulation is fully enforced, it is supposed to play a primary role in preventing traffic accidents. However, useful data about the Chinese regulation system are generally not available, and the available data might only be used for certain limited purposes. For example, several studies, through observation surveys, indicated that only the motor vehicle drivers show a higher rate of compliance with certain traffic safety regulations (i.e. stop at red lights) in China, whereas the rate of compliance is much lower among pedestrians and bike riders (especially the electric bike riders). These results are striking, because they reflect the fact that traffic safety regulation in China is poorly enforced in practice, especially among non-motor vehicles.

Rules regarding traffic liability can be efficiently enforced, if victims with meritorious claims can initiate claims and if those claims can be accurately resolved with respect to both liability and quantum rules (rules concerning the amount of damages to be given). In order to determine whether or not these conditions can be met in China, a comprehensive date set is needed. This data set is frustratingly not available in China. However, at the micro-level, there are several studies, indicating that only a small proportion of the traffic accident cases (approximate 10 percent) go to court in China. Moreover, the available evidence also provides some information, although very limited, on how traffic accident compensation claims are resolved in court. For example, some studies report that victims of traffic accidents are often considered to be partially at fault for their injuries and their compensation is regularly reduced. Some studies revealed that a relatively large number of judgements in China cannot 
be fully paid, because the prevalence of the insolvency problem. However, the existing evidence is unable to show whether victims with meritorious claims can successfully sue in court in China. Moreover, since most traffic accident cases are resolved through settlements and the outcomes of the settlements are largely unknown, we still know very little about traffic accident litigation in China.

When it comes to compensatory instruments, we found out that the enforcement of compulsory liability insurance is far from satisfactory in China. The duty to insure under the CVLI scheme is poorly enforced, particularly among motorcycles and tractors. Noncompliance with the duty to insure happens because those types of vehicles are mainly operated in rural areas, where the monitoring of the law and the consciousness of insurance are weak.

\subsubsection{Operation of the Traffic Accident Prevention and Compensation Instruments in Practice}

In order to assess whether certain traffic accident prevention and compensation instruments are actually operated as designed, it is necessary to first identify what these instruments aim for. Then, the weaknesses of these instruments in terms of achieving these aims as well as the reasons why these weaknesses occur are summarized.

Besides traffic accident prevention, the mixture of regulation and tort in China is also designed to achieve other aims, including but not limited to, punishing tortious acts, maintaining traffic order, improving the fluidity of traffic, protecting legal rights and interests, and promoting social harmony and stability. ${ }^{18}$ However, the laws (the TLL and the RTSL) fail to express clearly what the primary aim is. Without any doubt, there is a huge difference between whether, for example, punishment or protecting legal rights and interests is the primary goal. The same problem can also be found in the case of traffic accident compensation instruments. In addition to victim compensation, these instruments also provide a long list of aims without clear priority. In both cases, the question of the interplay of the multiple aims and their respective rankings arises. It is also unclear whether the traffic accident prevention and compensation instruments used in China have to reconcile these aims.

To make the analysis clearer, this research mainly focused on two well-recognized aims, that is, accident prevention and victim compensation. Other aims are only briefly discussed when necessary.

Operation of Traffic Accident Prevention Instruments. As mentioned earlier, China has established a framework for traffic accident prevention, which consists of both regulation and tort liability. Discussions in the previous Chapters suggested that some features of the Chinese traffic accident prevention framework are effective in theory. For example, the presumed fault liability and the $10 \%$ rule to protect pedestrians and cyclists from being disadvantaged by lack of evidence.

${ }^{18}$ See section 4.1 of Chapter 2. 
Even though it is difficult to assess whether the joint use of regulation and tort liability rules is effective in achieving the goal of traffic accident prevention in China, we do observe that since 2003, there was a decreasing trend for the number of traffic accidents in China. However, it is hard to prove whether this tendency can be attributed to the implementation of safety regulation or to the traffic liability system. Nevertheless, it does not mean that there is no evidence on the effectiveness of the traffic accident prevention framework in China. At the micro-level, as mentioned earlier, there are some studies, suggesting that the noncompliance with traffic safety regulation is more frequent among vulnerable traffic users than among motor vehicle drivers. Furthermore, some studies indicated that victims of traffic accidents in China are likely to face some obstacles in obtaining their payments no matter when their claims are settled within or outside of the court. ${ }^{19}$

The high rate of non-compliance among non-motor vehicles happens because the legislator's orientation in China is largely on enforcing safety regulation among motor vehicles rather than non-motor vehicles. This orientation needs to be changed, meaning that the Chinese legislator should pay equal or even more attention to punishing non-motor vehicles' wrongful behaviour and guarantee the strong enforcement of traffic safety regulation among those parties. In addition, when non-motorized traffic participants behave wrongly in China, their contributory negligence, if any, should be taken seriously into account.

The above-sketched ineffectiveness might also be attributed to the fact that traffic accident laws and regulations in China are often vaguely worded. Laws and regulations which regulate the traffic accident prevention instruments are usually surrounded by uncertainties. For example, it is unclear what is the definition of "fault"; what belongs to "rescue expenses"; what tests are needed to determine fault and causation; which evidence can be considered as "obviously-more-forceful"; what amounts to serious injury that qualifies for pain and suffering damages; how to put a monetary value on pain and suffering based on the given abstract benchmarks; lastly, how to apply contributory negligence and equitable liability? As a result, supreme court, local governments, and also academics often step in to provide detailed interpretations. However, some of these interpretations are inconsistent or even conflict with each other. Take the compensation for pain and suffering as an example. Different courts impose different caps on the amount of compensation, varying from 5,000 to 300,000 yuan. The inconsistency among laws and interpretations undoubtedly jeopardizes the effectiveness of the traffic accident prevention framework in China.

The lack of clarity in the legal texts may also lead to another problem. For instance, a large majority of the provisions in the RTSL (see Chapter VII) are framed in the following way: violating provisions in this law may result in a penalty of $X$ to $Y$ (a wide scope of range will be given). ${ }^{20}$ Moreover, article 24 of the TLL demonstrates that, in the cases where equitable liability applies, "losses shall be shared between the victim and the actor, based on the actual circumstances of the case." The problem with these types of provisions is that they do not clearly point out what the fine is or the circumstances are. In this case, public security officers and courts may have too much leeway to determine the amount of the fine or compensation. Consequently, they may abuse their power and cause corruption issues in practice. For example, according to one empirical study, nearly half of the drivers in the Zhejiang province

\footnotetext{
${ }^{19}$ See supra. section 3 of Chapter 6.

${ }^{20}$ The $10 \%$ rule in article 76 of the RTSL is also framed in the same way.
} 
have used some strategies to escape penalties when being caught, one of which is bribing the police officers (Fleiter et al., 2013, p. 7). ${ }^{21}$

All in all, the lack of clarity in traffic accident laws and regulations stands as an obstacle to swift decision making, thus increasing delays in the court. Such lack of clarity also makes the laws and regulations difficult to apply, especially taking into account the fact that in underdeveloped countries, the persons who apply the laws and regulations are often less educated and poorly trained (Cooter \& Schäfer, 2012, pp. 190-191). As a result, corruption and fraud issues are easier to hide and harder to detect in practice (ibid.). Ultimately, these problems are likely to become obstacles that stand in the way of realizing the goal of accident prevention.

Operation of Traffic Accident Compensation Instruments. In the previous section (section 1.1.1), we already pointed out that in China, a comprehensive framework has been used in practice to compensate victims of traffic accidents. However, simply having multiple instruments in place does not necessarily lead to full and effective implementation in practice. In fact, the operation of these compensatory instruments has the following problems.

Firstly, even though the CVLI, the tort system, optional liability insurance, social security schemes and first-party insurance are all used to compensate traffic victims in China, victims still face a relatively high possibility of being under-compensated. This under-compensation problem happens because unlike developed countries where social insurance by the state or private insurance purchased by individuals covers most accidents, insurance in China, like in most developing countries, is often confined to a limited group of people, i.e. rich people, public servants and workers from state-owned companies. Poor people, especially in rural areas, mostly lack insurance. As a result, the "uninsured out-of-pocket costs" (which refers to the victim's expenditure caused by the traffic accident, minus payments from insurance) are very high in China. ${ }^{22}$ This argument is further confirmed by one empirical study, which shows that in cases of traffic accident compensation claims, nearly 39 percent of accident costs are paid out of the tortfeasors' own pockets in Beijing (Zhou, Ju, \& Li, 2011, pp. 88-95).

Discussions in earlier Chapters also showed that victims in China rely heavily on the CVLI and on the tort system to obtain compensation in the events of traffic accidents. However, the implementation of the CVLI scheme is far from satisfactory. The duty to insure under the CVLI scheme is poorly enforced, particularly among motorcycles and tractors. Non-compliance with the duty to insure happens because those types of vehicles are mainly operated in rural areas, where the monitoring of the law and the consciousness of insurance are weak. Moreover, public critics also point to the ineffectiveness of the low amounts of coverage (max. 122,000 when the insured is liable or 12,200 yuan when the insured is not liable) and the heavily-regulated premium rates. There has also been a demand for a more refined BonusMalus system and greater competition in the insurance market. All these problems can, to

\footnotetext{
${ }^{21}$ This empirical study has already been discussed in section 4.3.2 of Chapter 2 .

${ }^{22}$ According to Cooter and Schäfer, "in low-income countries the average share of the 'uninsured out-of-pocket costs' is high and variable". This fact can be proved indirectly by the data on health expenditures, which shows how much the sick person pays himself, rather than insurance or the state paying. The out-of-pocket medical expenditures in China as a percentage of total medical expenses were $75.1 \%$ in 1997, whereas the number was only $16.6 \%$ in the US and $11.3 \%$ in Germany. See Cooter and Schäfer (2012, pp. 187-190).
} 
some extent, be attributed to the fact that the legislator in China has imposed too strict regulations on the CVLI premiums. Even though doing so may make CVLI more affordable to poor people, ${ }^{23}$ the legislator in China seems to ignore one important fact: the premiums of the CVLI should always reflect risks. Therefore, the insured, no matter how poor or rich they are, should always be charged a premium that reflects their risk. If not, or in other words, if the legislator or the government starts to offer subsidies to reduce the CVLI premiums in an effort to expand access to affordable CVLI for low-income people, they are subsidizing death. This may, at least in theory, lead to a high number of traffic accidents on the road.

Analyses in the previous Chapters also suggested that some characteristics of the CVLI are difficult to explain based on the current research. One of them is the Bonus-Malus system (BMS). The BMS under the CVLI is regulated in a peculiar way. Drivers who cause one fatal accident, which may just be the result of bad luck, face higher premium surcharges than those who cause two or more traffic accidents. And even worse, the BMS under the CVLI is not applicable to dangerous motorcycles and tractors. ${ }^{24}$ Given these features, it is highly doubtful whether the BMS under the CVLI would stimulate drivers to be careful and avoid accidents. Moreover, it is also very hard to explain why the victim's right to claim directly from the liability insurer is allowed under the OVLI but is prohibited under the CVLI. Is it purely accidental? Have the Chinese legislators thought of this difference? As these questions have not yet been sufficiently addressed, they point to interesting future research possibilities.

Since the CVLI only provides a relatively low amount of compensation, optional motor vehicle liability insurance (OVLI) becomes more popular among drivers, particularly in large cities and economically developed regions. According to the data collected by the CIIT, the percentage of automobiles with OVLI in China was as high as 76.4 percent in 2015. Compared to the CVLI, the OVLI scheme in China is less-regulated in the following aspects. Firstly, drivers have more coverage options (varying from 50k to 1 million) that they can select. Secondly, deductibles are allowed and the Bonus-Malus system is more refined. Thirdly, the victim's right of direct action against the OVLI insurer is allowed. Whether all these advantages of the OVLI can contribute to its increased popularity among drivers is a question that is difficult to answer. However, it will be another interesting topic for future research.

Since "uninsured out-of-pocket costs" are relatively high in China, victims of traffic accidents still often use the tort liability system to claim compensation. From a compensation perspective, some characteristics of the Chinese traffic liability system are problematic. The compensation for disability and death are on average very low. Also, the victim's right to access to compensation faces great barriers in practice. For example, in the cases of fatal traffic accidents, compensation awarded by the court amounts to 800,000 yuan on average. If the tortfeasors have no insurance coverage other than the CVLI, which is very common in economically underdeveloped regions, they will have to pay this high amount of compensation all by themselves. A problem of under-enforcement will be the result, where a relatively high proportion of judgements cannot be enforced or fully paid. Unsurprisingly, the

\footnotetext{
${ }^{23}$ The argument of affordability is given by the CIRC and is discussed in section 5.2.6 of Chapter 2 .

${ }^{24}$ The CIRC try to explain why the BMS is not applicable to motorcycles and tractors. They argued that initial premium rates for those vehicles are already very low. Therefore, even if the BMS were adopted for these vehicles, the trivial change in the premiums may still fail to incentivize drivers to behave safely. However, these arguments are not convincing. See supra. section 5.2.5 of Chapter 2 .
} 
under-enforcement of the judgements places huge obstacles on the effectiveness of the tort liability system.

Due to a lack of data, whether Chinese first-party insurance and social security schemes are capable of accomplishing their designed aims, is difficult to be measured. However, the available data shows that less than 20 percent of the whole population possessed some form of first-party insurance in China. When it comes to the social security schemes, it seems that those schemes are not widely used in traffic accident cases where only property damage and damages caused by a third-party are involved. By contrast, if the traffic accidents are caused by the social security beneficiaries themselves and result in injuries or deaths, and if the third party who caused the accidents cannot be found, social security schemes (usually the WII and $\mathrm{BMI}$ ) will often play a role in providing compensation. Moreover, in the latter category of cases, a right of recourse has been granted to social security carriers, whereas such a right is not allowed in the former category of cases. Even so, the issue of over-compensation is not very likely to happen in China, not only because double recovery of tort damages and social security benefits is only allowed in a limited number of cases but also because the benefits offered by the social security plans are restricted to an extremely low level.

\subsection{Answers to Research Question 3 and Main Findings from Chapters 3, 4 and 5}

Question 3: How can better accident prevention and victim compensation be achieved by utilizing different mechanisms in the light of law and economics theory? This question has been discussed in Chapters 3, 4, and 5.

In order to answer this question, the potential combination of regulation, tort liability, and various other compensation instruments (liability insurance, first-party insurance, social security, and public funds) is examined first (section 1.3.1- 1.3.2). Then, a concrete model which could create efficient incentives to prevent traffic accidents is proposed; and the necessary conditions to efficiently operate the traffic accident compensation systems are identified (section 1.3.3).

\subsubsection{Regulation versus Tort Liability}

The merits and weaknesses of regulation versus tort liability as a preventive mechanism are examined against Steven Shavell's four indicators. Applying those indicators to road traffic accidents reveals that neither regulation nor tort liability should be used alone to control the accident risk ex ante. This means that a smart combination of both is preferred. In order to achieve this smart combination, as suggested by the economic analysis, both regulation and liability rules should be efficiently designed on the one hand, and be effectively implemented and enforced on the other hand. To be more specific, the tort liability system should be used primarily to deter accidents and secondarily to spread loss and achieve other goals (i.e. corrective and social justice). As for the efficient design of liability rules, discussions in Chapter 3 shown that each liability rule has its own pros and cons (see Figure 7.1a and 7.1b, next page).

Therefore, the ultimate choice always depends on a weighing of all these pros and cons; hence searching for a trade-off among various factors (i.e. the availability of information, the capacity of courts, the risk of insolvency, the importance of controlling activity level). 


\begin{tabular}{|l|l|}
\hline \multicolumn{2}{|c|}{ Figure 7.1a The Rule of Negligence } \\
\hline Pros & Cons \\
\hline injurer will take optimal care under unilateral accident settings & victim will take suboptimal care under bilateral accident settings \\
\hline both parties will take optimal care under bilateral care accident settings & victim will not perform optimal level of activity under unilateral accident settings \\
\hline both parties will take optimal care under bilateral harm accident settings & Information regarding the determination of negligence is difficult and costly to acquire \\
\hline
\end{tabular}

\begin{tabular}{l|l|}
\hline \multicolumn{1}{|l}{ Figure 7.16 Strict Liability } \\
\hline Pros & Cons \\
\hline injurer will take optimal care under unilateral accident settings & both parties will take suboptimal care under bilateral harm accident settings \\
\hline injurer will take optimal care under bilateral accident settings & victim will not perform optimal level of activity under bilateral accident settings \\
\hline both parties will perform optimal levels of activities under unilateral accident settings & both parties will take suboptimal care and activity if there is a risk insolvency \\
\hline
\end{tabular}

Both strict liability and the rule of negligence are preferred in case of classic unilateral accident settings (where only the injurer can invest in care to avoid the accident), ${ }^{25}$ provided that liability standards are optimally set, the level of activity is constant, information is perfect, and the legal sanctions are equal to harm. ${ }^{26}$ Relaxing the first and the second assumptions provides further insights favouring the use of strict liability. One major drawback of strict liability in unilateral accidents arises when we relax the last assumption, that is, damages are not perfectly compensated and there is a risk of insolvency. However, the advantage of strict liability over the rule of negligence in case of insolvency should not be over-stated, if one further takes into account the fact that in practice, liability for negligence rises continuously and other instruments (i.e. insurance) might already address insolvency issues. ${ }^{27}$

When it comes to the classic bilateral accidents (where both the victim and the injurer can take precautions to reduce the accident risk), neither strict liability nor the rule of negligence will lead to efficient outcomes, unless a defence that could take into account the victim's fault (contributory or comparative negligence) is added. ${ }^{28}$ However, if it is more important to control the injurer's activity than the victim's, ${ }^{29}$ strict liability might be preferred and should better be companied with the defence of contributory or comparative negligence. Even though the conclusions that we draw from the classic accident models only take into account the unilateral harm situation (where only one side is harmed), these conclusions remain valid for the bilateral harm situation where both sides are injured. ${ }^{30}$

Besides a careful design of the liability basis, economic analysis also proposed the following principles in designing an efficient tort system, or more particularly an efficient traffic liability system. The first principle is that the tort system should be combined with certain mechanisms to deal with various types of uncertainties, such as the uncertainty over the standard of care and the uncertainty over the assessment of each tortfeasor's fault

\footnotetext{
${ }^{25}$ The classic unilateral accidents can also be referred to as "unilateral care and unilateral harm accidents".

${ }^{26}$ See supra. sections 2.1 and 2.2 of Chapter 3.

27 Ibid.

28 The classic bilateral accident can also be called as "bilateral care and unilateral harm accidents".

${ }^{29}$ For example, it is more important for the government to control the motor vehicle driver's activity than the pedestrian's as one society apparently suffers from more pollution while driving a car than walking.

${ }^{30}$ To make it clear, a few of the motor vehicle versus non-motor vehicle accidents can be considered to conform to the classic unilateral accident settings, whereas most traffic accidents are in line with the classic bilateral accident settings. All types of road traffic accidents may suffer either unilateral or bilateral harm, even though unilateral harm is more likely to happen in accidents between motor vehicles and non-motor vehicles.
} 
contribution. One way to reduce these uncertainties is to rely on the appraisal report issued by the experts. Another way is to refer to the regulatory standards/rules which are made by various sectors of the government (i.e. traffic safety department) based on their professional knowledge and comprehensive data. Moreover, an efficient tort system also requires that no caps are imposed on liability, since arbitrary caps may create insufficient care levels. Lastly, in order to function efficiently, tort damages should be cautiously calculated, preferably in the light of proper (correct on the average) and objective estimates.

\subsubsection{Comparison of Different Compensation Instruments}

Economic analysis of the accident law equally argues that even the combination of regulation and liability rules cannot guarantee efficient prevention and risk distribution (or compensation). One reason is that these two instruments focus mainly or even solely on the goal of prevention, the goal of victim compensation is partially neglected. Another reason is that the efficiency of the tort system may be undermined by various problems, such as the insolvency risk of liable parties and information asymmetry. In order to remedy these problems, a holistic approach, or a toolbox is needed, where the liability system should be accompanied by other compensation instruments, such as liability insurance, first-party insurance, and social security schemes. Moreover, it should be noted that within the holistic approach, the liability system and other compensation instruments are interrelated. This means that they should develop hand-in-hand rather than independently.

In Chapter 5, this research examines three types of compensation instruments (liability insurance, first-party insurance, and compensation schemes that are not based on fault) individually in the light of Calabresi's social costs theory. ${ }^{31}$ This examination is necessary because it clearly shows the strengths and weaknesses of each instrument. The results are summarized as follows.

Tort Liability and Insurance. Tort liability can be used as a mechanism for accident victims to seek compensation, only if liability can be established or a liable person can be found. Otherwise, the victim will not be compensated. ${ }^{32}$ This may be the case with the accidents that are caused by human errors, but for instance not the case where the accident was caused by force majeure. The victim is able to receive through tort law, only if a potential injurer can be held liable and is solvent (i.e. the injurer has liability insurance to cover her obligations). If those conditions cannot be satisfied, victims can turn to first-party insurances (i.e. personal accident insurances or vehicle damage insurance) for help. Coverage of those insurance products is usually provided in a lump sum and is paid irrespective of the cause of the accident. Moreover, first-party insurance is often voluntary to buy in most legal systems and the scope of coverages is always dependent upon policy conditions.

Moreover, losses caused by traffic accidents might be substantial, especially in cases where serious injuries and deaths are involved. ${ }^{33}$ The injurer, who is facing such huge losses, is often risk averse. The injurer's marginal utility of wealth could be improved through risk-spreading

\footnotetext{
${ }^{31}$ See supra. sections 2, 3, and 4 of Chapter 5.

32 See supra. sections 1, 2, and 7 of Chapter 3.

${ }^{33}$ Empirical evidence on the compensatory role accomplished by the traffic liability system was discussed in section 1.3.1 to 1.3.6 of Chapter 4 .
} 
mechanisms. Except for the mechanisms that are based on the assets of the injurer himself/herself (i.e. personal savings), other compensation mechanisms may also have riskspreading effects. In fact, insurances (liability insurance and first-party victim insurance) enable accident parties to shift at least part of their liability or losses to a large pool of policyholders, through paying a small amount of money. ${ }^{34}$ Moreover, to the extent that insurances are mandatory or are bought by most citizens on a voluntary basis, accident parties' liability or losses are further shifted to society at large. ${ }^{35}$

Since insurances are often used to provide compensation to the victims of traffic accidents, the question of how to guarantee their effectiveness has been debated hotly in the law and economics literature. From an economic perspective, through transferring the risk of high damage to a fractional premium, insurance helps to increase the utility of the insured party's risk averseness. As long as the premium corresponds with the actual risk, the deterrence effect remains valid. Most importantly, in order to function efficiently, the well-known moral hazard and adverse selection problems need to be properly controlled by the insurer. This can be done by close monitoring, differentiating risks and allowing deductibles. Moreover, a sufficiently competitive market is also crucial for an insurance scheme to function effectively, especially when such schemes are compulsory.

The choice between third-party (liability) insurance and first-party (victim) insurance has also been discussed extensively among economists. ${ }^{36}$ The results showed that first-party insurance is superior to liability insurance, because better risk-differentiation can be achieved without incurring higher transaction costs. Moreover, with first-party insurance, a person enjoys the benefit of choosing their own insurance. Also, the insured person could ensure that they have as much coverage as needed. However, not everything is great about the firstparty (victim) insurance. ${ }^{37}$ For example, the insured's premium may be increased, even if (s)he is not at-fault in an accident (because it is the insured's insurance company who is paying for the damage). By contrast, liability insurance only punishes the insured for being liable in an accident, not for just being involved in an accident. This incentivizes the drivers to drive carefully and might lead to a safer driving environment.

Whether those insurance schemes are so good that they should be made mandatory is a separate topic. Economic analysis suggested that in the case of an insolvency risk, a duty to take financial coverage, often taking the form of compulsory liability insurance, should be introduced. Otherwise, tort law may fail to have its deterrent effect. ${ }^{38}$

Social Security. The incentives for victims to use tort law to obtain compensation will not be very strong, if other compensation systems, for instance the social security system, are widely available. As far as personal injury is concerned, victims in some legal systems, particularly those in Western European countries, often rely primarily on the social security system to

\footnotetext{
${ }^{34}$ The rationale of insurance in terms of loss-spreading was discussed in section 5.1 of Chapter 3.

${ }^{35}$ See supra. sections 4.3.1 and 4.3.2 of Chapter 5 .

${ }^{36}$ See supra. section 3.1 of Chapter 5. One recent article provides a nice review of the economical debate over first-party insurance versus liability insurance. See Avraham (2012, pp. 29-112).

${ }^{37}$ See supra. section 3.2 of Chapter 5.

${ }^{38}$ The discussion of whether the mandatory duty to insure should be introduced has been discussed in sections 4.3.1 and 4.3.2 of Chapter 5.
} 
obtain compensation. The social security scheme will provide the victims with a basic guarantee against income losses, medical bills and health-care expenses, if certain conditions can be met (i.e. the victim belongs to the protected group and the losses fall within the insured risk). ${ }^{39}$ Moreover, when the injury is work-related, the compensation is often more generous than when it is not the case. Compared with European countries, the social security systems in almost every developing country, as well as in the US, are less generous. However, it should be noted that, no matter how generous the social security system is, it only covers a part of the victim's loss. This holds true for both developing and developed countries. For losses that are not covered by social security, victims (usually wealthier ones) will have to look for additional compensation systems, where tort and insurance are primarily the indicated systems. ${ }^{40}$

In fact, by charging income-dependent premiums, social security schemes normally play a redistribution rather than a risk-spreading function. ${ }^{41}$ This means that there is a redistribution of wealth from low-risk participants to high-risk participants, as social security beneficiaries are paying the non-risk-related premiums. Moreover, since some social security services (i.e. social assistance schemes for really poor people) are provided for free, the problem of moral hazard arises. However, remedies for this problem (such as detailed control of the insured and risk-differentiation) are often restricted under social security schemes because of a "solidarity" concern. Moreover, even though partially exposing the insured to the risk (i.e. via deductibles) is another way to eliminate the moral hazard problem, this remedy is sometimes applied to large risks. As a result, high deductibles are adopted and the problem of overdeterrence arises. Given all these deficiencies, law and economics scholars often argue that social security schemes make more sense from the perspective of risk-distribution than from the perspective of risk-spreading.

Alternative Compensation Systems. In contrast with the tandem of tort and insurance, and social security, there are other mechanisms that can also be used to provide accident compensation to victims. These mechanisms are introduced, at least in some countries, mainly because victims are still left inadequately protected even after using all the traditional instruments mentioned above. For instance, this may be the case when no liable person can be identified or when the injurer proves to be insolvent. In many legal systems, compensation funds are therefore introduced to cover damage caused by uninsured motor vehicles or by hit-and-run drivers. In those cases, the compensation funds have a supplementary character, which means they can be used only if traditional compensatory mechanisms do not provide an adequate remedy.

Alternative compensation systems may even completely replace the tort/insurance model. ${ }^{42}$ Some scholars argue that the tort system does a poor job (too slow and costly) of delivering accident compensation and spreading risks (if potential injurers are insolvent). ${ }^{43}$ Even though

\footnotetext{
${ }^{39}$ The rationale of social security has been discussed in section 4.4 of Chapter 5 .

${ }^{40} \mathrm{An}$ an overview of the law and practice of compensation for personal injury in ten European jurisdictions is provided by Koch and Koziol (2003, pp. 1-514).

${ }^{41}$ See supra. section 4.4.1 of Chapter 5.

42 The advantages and disadvantages of alternative compensation mechanisms have been summarized in sections 4.1 and 4.2 of Chapter 5.

${ }^{43}$ The empirical evidence on the ineffectiveness of tort law in providing accident compensation was summarized in Chapter 4. See supr. Sections 1.3, 4.1, and 4.2 of Chapter 4.
} 
the tort system is worth being preserved on the grounds that it has deterrent effects, this deterrence role could also be accomplished by safety regulation, backed up by administrative and criminal sanctions. For instance, in the area of traffic liability, some authors even argued that the tandem of liability and insurance rarely have a deterrent function and proposed a socalled no-fault model for victim compensation (Tunc, 1996, pp. 329-340). This no-fault model has already been adopted in several countries (i.e. France, Scandinavian countries, and some states in the US), but the exact shapes are different. ${ }^{44}$ Since the coverage provided under the no-fault compensation schemes is triggered by the damage instead of by tort liability, these schemes are able to provide faster compensation and better risk distribution with fewer errors and fewer uncertainties, compared to the joint use of tort and liability insurance. Moreover, the no-fault schemes are also praised for their ability to save administrative costs. However, it cannot be ignored that no-fault compensation schemes have one serious weakness, that is, recovery for non-economic damages (i.e. pain and suffering) is normally not allowed under those schemes. Therefore, the amount of compensation under those schemes is generally lower than what would be awarded under tort law. Moreover, since nofault schemes are basically not fault-based (neither the compensation offered by these schemes nor their financing is fault-related or risk-related), they are likely to raise problems in the preventive dimension. As a result, the no-fault schemes can have a negative impact on care behaviour and may eventually harm traffic safety.

The above-listed theoretical hypotheses are also confirmed by many empirical studies. On the one hand, a vast number of empirical studies, most of which are US-oriented, proved that nofault compensation schemes were capable of providing compensation within a shorter period and at a lower cost than tort. On the other hand, several empirical studies suggested that the shift from tort to no-fault for automobile accidents may lead to more fatalities and more sever traffic accidents on the road..$^{45}$ However, the rate of increase may vary, both across different countries and across different versions of no-fault (pure no-fault and mixed no-fault). ${ }^{46}$

\subsubsection{Are There Any Optimal Models?}

After all the above-mentioned comparisons, it becomes clear that a smart combination of regulation and tort liability system is needed to prevent accidents from happening. At the same time, for those inevitable traffic accidents, a holistic approach, or in other words, a toolbox seems to be more beneficial to compensate victims. Admittedly, these conclusions are too vague to apply. However, providing precise clarifications is extremely difficult, since the smart combination of regulation and liability as well as the exact shape of the compensation toolbox varies among different jurisdictions. Therefore, there does not exist one universal model that fits all legal systems. The answer varies across different legal systems and depends upon various factors, including but not limited to, the enforcement of regulation, the shape of liability rules, the maturity of the insurance market, the financial situation of the government, and legal culture.

Models for Traffic Accident Prevention. Being aware of the strengths and weaknesses of regulation versus tort liability and considering both the goal of prevention and the goal of

\footnotetext{
${ }^{44}$ See supra. section 4.1.1 of Chapter 5.

${ }^{45}$ See supra. sections 4.2.1 and 4.2.2 of Chapter 5.

46 Ibid.
} 
compensation, this research first proposes two models for accident prevention, depending mainly on whether one country is developed or not (See Table 7.2). These two models are not immutable. This means that when a developing country becomes more developed, it can also fit in the model that is designed for the developed countries. In both of the proposed models, regulation and tort liability should in principle be jointly used to deter traffic offenders on the road. However, the joint use of these two instruments leads to high administrative costs. Moreover, one has to place a lot of trust in the regulators and enforcers. Thus, in order to save costs, the tort liability system may not be needed, where there is sufficient compliance monitoring and enforcement to deter traffic-regulation offenders, and/or where citizens' sense of morality is sufficiently high. Notably, the abolition of liability law should be really exceptional. ${ }^{47}$ Not only because the full enforcement of safety regulations would never be possible, but also because many people still need material incentives to protect others from accidents, and liability law could provide this.

\begin{tabular}{|c|c|c|c|}
\hline Developed Country & Remarks & Under-developed Counrty & Remarks \\
\hline \multirow[t]{4}{*}{ Regulation } & - Guarantee the enforcement of regulation & Regulation (more important) & - Clearly defined legal texts \\
\hline & & & - Regulatory standards should be low \\
\hline & & & - Be backed up by small fines that are imposed with high probability \\
\hline & & & - Pay attention to corruption issue of administrator \\
\hline \multirow[t]{10}{*}{ Tort liability } & - May even not be needed if regulation is fully enforced and & Tort liability & - Clearly defined liability rules \\
\hline & citizen's sense of morality is sufficiently high & & - Levels of due care could be lower \\
\hline & - Basis of liability depends on different accident models & & - Better impose strict liability on parties with insurance. i.e. car drivers \\
\hline & - Use appraisal report issued by police to reduce uncertainties & & - Use appraisal report issued by police to reduce uncertainties \\
\hline & - No arbitrary caps on liability & & - Levels of compensation should be lower \\
\hline & - Estimates used to calculate damages should be correct on average & & - No arbitrary caps on liability \\
\hline & - Try to avoid frivolous compensation claims & & - Estimates used to calculate damages should be correct on average \\
\hline & & & - Introduce flat rate/ fixed sum of compenstaion; regularly update is needed \\
\hline & & & - Legal aid is needed to avoid "trial proof" \\
\hline & & & - Contingent fees are needed to ensure poor victim can access to court \\
\hline
\end{tabular}

Even though the joint use of regulation and tort liability is preferred in both accident prevention models, within each model, the focus might be different. Generally speaking, the best balance between regulations and a tort liability system depends both on the institutional capacity of regulators and on the judiciary in the country in question. More specifically, in under-developed countries, the tort liability system is often less effective in terms of deterrence due to two reasons. ${ }^{48}$ One is that injurers are likely to be insolvent and cannot pay liability judgements (the injurers are "judgment proof"). Another reason is that poor accident victims cannot pay lawyers to sue their injurers (the poor victims are "trial proof"). To ameliorate these problems, as Cooter and Schäfer suggested, under-developed countries should control accidents by relying more on regulation and less on liability law, compared to developed countries (Cooter \& Schäfer, 2012, p. 191). Moreover, the preference of regulation versus tort liability may also depend on who the policymakers trust most. If they trust police more than judges, they may show more reliance on regulation, whereas if they trust judges more than police, the tort system is more reliable.

\footnotetext{
${ }^{47}$ For example, only New Zealand has totally abandoned tort law remedies for injuries caused by all accidents and replaced it with a government-funded insurance scheme. The no-fault system in New Zealand has been studied by a number of researchers. See among many others Henderson (1981, pp. 781-801) and Brown (1985, pp. 976-1002).

${ }^{48}$ These reasons are discussed in Cooter and Schäfer (2012, pp. 179-192).
} 
Within each model, the detailed features of individual instruments might be different as well. In under-developed countries, in order to make safety regulations more effective, they would be better backed up by small fines that are imposed with high probability (ibid., pp. 185-186). Also, regulations in under-developed countries should rely more on clearly defined legal texts and less on vaguely worded principles, in order to avoid corruption and fraud issues and to make regulations easy to be applied (ibid., pp. 190-191). For similar reasons, clarity in the texts of liability law is also very important. This means that the courts in under-developed countries should adopt clear-defined legal rules to determine liability and should introduce flat-rate compensation for certain categories of losses (ibid.).

Lastly, when one country is under-developed or in transition, the people there often have less money to spend on safety, just as they have less to spend on food, insurance, and everything else. Liability law, as law and economics analysis often suggested, will incentivize individuals to take the same care towards strangers as they take towards themselves. If this ideal situation were realized, liability law would lead people to spend less on the safety of others in under-developed countries than in developed countries (ibid., pp. 180-184). Following this argument, regulatory safety standards, levels of due care, and levels of tort damages should all be set substantially lower in under-developed as compared to developed countries (ibid.). Furthermore, since accident victims often lack insurance in under-developed countries, liability law in those countries should shift accident costs to the party with most access to insurance (i.e. automobiles drivers) (ibid., pp. 187-190). And to increase access to courts, under-developed countries should either provide legal aid to poor victims, or allow victims to pay their lawyers with contingent fees ${ }^{49}$ (ibid., pp.184-187).

Indicators for the Efficiency of Compensation Models. When it comes to the optimal model for traffic victim compensation, it is extremely difficult to provide a defined answer. The exact shape of the compensation toolbox may even be different among countries that are at the same stage of development, as governments may have different priority concerns, which may even change over time. ${ }^{50}$ Given these facts, instead of proposing concrete compensation models, the existing law and economics studies normally identify the necessary conditions for the design of an efficient traffic victim compensation model (see for example, Vickrey, 1968, pp. 484-487; Skogh, 1989, pp. 87-101; and Fiore, 2009, pp. 418-422). ${ }^{51}$ What they suggest is not to choose the most suitable instrument in one specific situation, or to use several instruments equally when they all fit. Instead, a toolbox that includes various instruments for different tasks should be advocated. Based on the existing literature and also taking into account the differences between developed and developing countries, this research provides the following indicators to guide the choice and the design of the compensation models for RTA victims.

\footnotetext{
${ }^{49}$ Contingent fees are a fee charged for a lawyer's services only if the lawsuit is successful or is favorably settled out of court. So it shifts the financial burden of initiating litigation from the plaintiff to the plaintiff's lawyer.

${ }^{50}$ For example, social security schemes traditionally play an important role in providing accident compensation. However, with the spread of the economic crisis, some European countries (i.e. Netherlands) tended to reduce social security payments, which increases the victim's need to use tort law to claim compensation. See Faure \& Hartlief (2003, pp. 223-265).

${ }^{51}$ These studies have already been discussed in Chapter 3 and 5.
} 
The first indicator is the policymaker's top concern. If the policymaker's priority concern is rapid victim compensation or victim protection, the strict liability system ${ }^{52}$ as well as other non-fault-based compensation schemes, such as first-party insurance, social security, and nofault insurance, can all be suitable for the job. As for the strict liability system, in order to provide full compensation and to avoid under-deterrence, this system should not impose any limitations on compensation amounts. However, it should be noted that unlimited liability is purely theoretical, given the fact that the injurer's financial assets are always limited. Therefore, even if the injurer's liability is unlimited, (s)he will only be induced to protect his/her whole resources and nothing more. Nevertheless, injurers with unlimited liability will surely perform higher levels of care than those with a liability cap, which may justify the use of uncapped liability. Moreover, under the strict liability system, the compensation should in principle be provided by the private sector (the injurer and liability insurer). And if needed, the government's intervention might be required. For example, the government could intervene through increasing the amount of compulsory insurance coverages, when compensation is above the injurer's liability cap or if the injurer's assets have been used up in the case of unlimited liability. The government might also intervene by paying direct compensation to the victim if the tortfeasor cannot be found. With respect to the social security schemes, besides providing fast compensation, those schemes can also be used to achieve the goal of "solidarity". Therefore, if the policymakers intend to emphasize on the equal access to health care, social security must be included in the toolbox. When the nofault schemes and the tort system are jointly used, the problem of over-compensation may arise. In order to remedy this problem, a right of recourse should be largely granted to insurers and social security carriers. Also, the collateral sources set-off rule should be applied. The emphasis of the goal of compensation does not necessarily mean that the goal of accident prevention should be ignored. In order to maintain the deterrent effect, the instruments in the toolbox should properly control the issues of moral hazard and adverse selection. This task could be accomplished by adopting deductibles, imposing caps on insurance coverage and using risk-differentiated premiums.

By contrast, if the policymaker gives equal importance to both the goal of accident prevention and the goal of victim compensation, the strict liability system should be used. The reason is that the strict liability system manages to combine the respective advantages of no-fault (fast compensation ${ }^{53}$ and protection of victims) and negligence systems (care incentives). Moreover, to be sufficiently deterrent and to maximize the protection of victims, the strict liability system needs to be coupled with a variety of additional legal instruments, including un-capped liability, safety regulation, financial securities (i.e. compulsory insurance), and government intervention.

\footnotetext{
52 The strict liability system can be regarded as a hybrid legal system, which is halfway between the no-fault and negligence systems. The differences between the strict liability system and no-fault schemes are explained by Karine Fiore. See Fiore (2009, pp. 406-432).

${ }^{53}$ Compared to the rule of negligence, the courts do not have to determine fault under strict liability. In this regard, we can argue that strict liability is able to deliver fast compensation. However, strict liability still falls within the scope of the tort regime, implying that causation and damages need to be proved by the claimant to receive indemnification. From this perspective, strict liability may fail to provide fast compensation, especially compared to those schemes where compensation to the victim is totally unconnected with the tortfeasor's liability.
} 
Note that the policy-maker might, in some cases, care more about accident prevention where the compensation toolbox gives higher priority to accident prevention than to compensation. In other words, there might be a case where the compensation toolbox is mainly used as an instrument to achieve the goal of accident prevention. In this case, the tort system must be included in the compensation toolbox, as it gives priority to prevention, whereas the others (such as social security and no-fault) give priority to compensation. The tort system can either be fault-based or non-fault-based (strict liability). No matter whether the tort system is based on fault or not, it would be better to make sure that certain solvency guarantees, like compulsory insurance, are already in place. Especially when the rule of strict liability is applied, liability insurance would be better if made mandatory in order to alleviate the risk of judgement-proofing. Also, in order to generate efficient deterrence, compulsory insurance schemes should allow insurance companies to differentiate risks. Moreover, when the tort system is included in the compensation toolbox, two more conditions have to be fulfilled, in order to guarantee the tort liability system's efficiency in accident prevention. Firstly, the injurer's liability should in principle not be financially capped. Secondly, safety regulation should be used simultaneously with the tort system, in order to strengthen the deterrent effect.

The second indicator that may influence the choice is whether the insurance market is mature or not. For example, if insurance markets are immature and highly-concentrated, insurers will have little incentive to do risk-differentiation. Consequently, the implementation of a mandatory insurance scheme will lead to low quality but high price insurance products. Given these concerns, when implementing a compulsory insurance scheme in under-developed insurance markets, the policymakers need to make sure that the insurance market is competitive, and they also need to impose some limitations on the insurer's capacity to control moral hazard. Moreover, when insurance markets are immature, first-party insurance, social security schemes, and no-fault insurance schemes, if any, may not develop very well. This can also happen in legal systems where the governments have poor financial situations, because the development of those no-fault-based compensation schemes normally requires high investment on the government's side. Therefore, it seems beneficial for immature insurance markets to rely less on no-fault schemes (i.e. first-party insurance, social security, or no-fault insurance), but more on the combination of tort system (based on fault or strict liability) and liability insurance (preferably on a compulsory basis).

Lastly, the choice of different compensation instruments may be influenced by the issue whether a liable party can be identified or not. If the liable party cannot be identified or located, a public compensation fund should be used. Moreover, this fund would be better if contributed by potential injurers rather than the general revenues and be more risk-related.

Therefore, in order to establish an optimal toolbox for victim compensation, it is necessary for legislators in one country to go through all the above-listed indicators and to select the suitable instruments. Moreover, legislators should also notice that the toolbox can be used not only to offer compensation to victims but also to promote better risk spreading practices. Notwithstanding the benefits that are brought by the compensation toolbox, those benefits should always be balanced with the costs of using the toolbox. On this point, empirical findings could provide further guidance. 
Admittedly, those indicators are merely a simplification of the reality, even though they indeed provide some useful insights in choosing among various instruments. To apply those indicators correctly and effectively in practice is still a sophisticated task and more empirical work is needed to guide the application. This is therefore undoubtedly a territory that deserves to be carefully developed in the future.

\subsection{Answers to Question 4 and Main Findings from Chapter 6}

Question 4: Do the legal instruments for road traffic accident prevention and compensation in China make any sense from a law and economics perspective? If not, what are the problems? This question has been discussed in Chapter 6.

Applying the economic criteria to analyse the situation in China shows the following results. First, although China has implemented intensive regulations on traffic safety, these regulations are not fully enforced in practice. In this context, the use of the tort liability system can be justified from an economic perspective, as it could provide an additional deterrence effect. In fact, some features of the Chinese traffic liability system (i.e. the basis of liability, the practices developed by the court to establish fault and causation, the defence that takes into account the victim's fault) are, at least on paper, in line with the economic models. However, because of the application of the equitable liability and the $10 \%$ rule, there may exist an over-deterrence issue, which is not in conformity with economic insights.

Despite all of these merits, some aspects of the Chinese traffic liability system do not fit well with economic analysis. Firstly, the aims of the tort liability system, and particularly the traffic liability system, are not properly set. Some of the aims, such as punishment and compensation, are incompatible or even in contradiction with each other, whereas others (i.e. promoting social harmony) have a vague meaning. As a result, it is unclear what the traffic liability system really aims at and which aim has higher priority in China. This lack of clarity also fails to provide any clear indications for policy-making.

Under the tort liability system, how should damages caused by traffic accidents be assessed is another essential issue, because the assessment will ultimately influence the goal of deterrence. In China, the assessment guidance is relatively accurate in cases where only minor injuries and property damage are involved. However, the estimates used to calculate the values of serious injuries and death are incorrect. Even worse, the local courts in China tend to impose arbitrary caps on the compensation for pain and suffering. Unsurprisingly, victims of traffic accidents are likely to be under-compensated, especially in cases where the victims are seriously injured and dead. Moreover, in those cases, since the amount of compensation often exceeds the injurer's wealth, the under-compensation problem will ultimately lead to under-deterrence.

The above-mentioned problems show that when functioning as a compensation instrument, the traffic liability system in China does not work well. Inefficiencies exist not only on paper but also in practice. The available data, although quite limited and incomplete, shows that eligible victims cannot obtain compensation easily and quickly mainly because of two reasons. Firstly, when the compensation claims are settled in court, the trial takes a long time (usually 3 to 6 months), and a considerable proportion of judgements issued by the court cannot be 
enforced or fully paid. Secondly, when the compensation claims are settled out of the court, the victims often receive less compensation than in the court.

When it comes to the compensatory instruments, the situation in China clearly shows that merely having them in place does not lead to effectively implementing them in practice. As a result, the adopted compensation instruments often fail to function effectively, in terms of both compensation and deterrence. As mentioned earlier, the goal of compensation is primarily achieved via the CVLI. However, the CVLI does not conform to the economic analysis in the following ways. Firstly, the CVLI is supposed to cover all motor vehicle drivers in China. In practice, however, the duty to insure is often not observed by motorcycle and tractor drivers, due to the uneven distribution of the police force and due to corruption issues. The under-enforcement of the duty to insure apparently deviates from the optimal model, posing hurdles to the realization of compensation. Secondly, the CVLI in China imposes heavy regulations on the initial premiums, the Bonus-Malus system and the coverage. This causes serious adverse selection issues and less serious moral hazard problems (because the coverages under the CVLI are still low). These problems will, as suggested by the law and economics literature, distort the deterrence effects created by the traffic liability system.

Moreover, in the Chinese CVLI system, the victim's right to directly claim compensation from the insurer is forbidden. However, such action is allowed under OVLI, which is difficult to explain. The exclusion of the direct action does not make any sense from an economic perspective, because such action saves administrative costs. Lastly, under the CVLI, the insured's deterrence incentives may further be distorted, not only because the insurance coverage is not closely linked to the insured's fault and liability, but also because the insurance market in China is still monopolized.

Since the protection offered by the CVLI is insufficient, Chinese automobile drivers, especially those in large cities, choose to carry OVLI in addition to the CVLI. Compared to the CVLI, coverage provided under the OVLI is higher and OVLI products are not subject to strict regulations. Problems of moral hazard and adverse selection are therefore better controlled, partially restoring the under-deterrence problem caused by the CVLI. However, the merit of OVLI should not be over-stated, because the cost of such insurance is higher than CVLI and is only popular in economically developed regions.

The popularity of OVLI in China is striking but difficult to explain from a law and economics perspective. Economists generally accept that the imposition of liability creates a demand for liability insurance. Such insurance can be used to finance a liability exposure when private markets fail to internalize this cost. However, liability insurance merely covers property damages and bodily injuries done to others. If people want to protect themselves or their own assets from an accident, they should purchase first-party insurance policies (i.e. accidental injury insurance, collision insurance). Apparently, the economic analysis of insurance alone is not sufficient to explain what is going in the Chinese automobile insurance market. The percentage of drivers with liability insurance is far more numerous than those with first-party insurance in China. ${ }^{54}$ In other words, Chinese drivers clearly prefer to buy OVLI more than first-party insurance to protect themselves against accidents.

\footnotetext{
${ }^{54}$ Here, first-party insurance refers to the first-party insurance purchased by the potential injurer.
} 
The high OVLI ownership rate in China may have something to do with the fact that there is a "hidden part" of the OVLI, which provides first-party coverage for the driver and passengers in the car. In fact, certain types of first-party auto insurance, such as driver and passenger insurances (which cover injury to, or death of, the driver and passengers), must be purchased additionally to the basic OVLI coverage in China. ${ }^{55}$ Hence, when counting the number of people with OVLI, statisticians may include the drivers who have driver or passenger insurance. However, these drivers might be excluded when counting first-party insurance.

It should be noted that in road traffic accident cases, even though OVLI, first-party insurance, and social security can also play a role in compensating victims, their roles are very limited in China. Compared to the CVLI, the OVLI products are more risk-based and hence better riskdifferentiation has been achieved. However, the merits of OVLI should not be over-stated, because only people from economically developed regions have purchased such insurance. The efficiency and effectiveness of the first-party insurance and social security schemes are difficult to assess, because they are not widely used to compensate traffic victims in practice. First-party insurance is rarely applied, due to the fact that only a small proportion of the population are covered by such insurance. Social security schemes are only used in limited numbers of cases, where personal injuries and deaths are involved and where the injuries and deaths are not caused by the third-party (an exception is where the third party fails to pay or cannot be identified). This rule is likely to cause difficulties in practice, because in order to obtain fast compensation, the "smart choice" for the victim is to keep silent or even lie about who caused the accident. Moreover, the benefits provided under the social security schemes are extremely minimal. Even worse, the social assistance schemes, that are designed to help poor victims, will only provide benefits upon request. Because of complicated application procedures and minimal benefits, it comes as no surprise that victims of traffic accidents are reluctant to use social security schemes to obtain compensation in practice.

Summing up, primary accident costs seem to be relatively high in China, mainly because the combination of the traffic liability system and safety regulation are weakly enforced and can only achieve partial deterrence in practice.

When it comes to secondary accident costs, our analyses show that in China, the compensation awarded to the victim is often low and the risk of insolvency is relatively high. Moreover, since the legislator strictly limits the insurer's ability to differentiate risks, there is no adequate risk-differentiation in the Chinese CVLI market. All these problems have, to some extent, been confirmed in practice. Therefore, in China, the compensation toolbox that is used in traffic accident cases does a poor job of loss spreading. As a result, the secondary accident costs in China are relatively high, both on paper and in practice. This problem is of great importance in current China, because China has a more pressing need for adequate riskspreading than in high-income countries. This is because the marginal value of one dollar for poor people is higher than for the rich. Given this diminishing marginal utility of wealth,

\footnotetext{
55 There are four types of additional insurance that drivers can buy for their vehicles, including driver and passenger insurance (cheshang renyuan zeren xian), carriage of goods damage insurance, liability insurance for loss of goods and no fault loss compensation insurance (wu guocuo sunshi buchang xian). See CIRC's explanation on basic OVLI coverages and additional coverage, available at http://www.circ.gov.cn/web/site47/tab4335/ info181342.htm (in Chinese).
} 
people from China, who have relatively less wealth, will be more risk averse to large risks than those from high-income countries.

Lastly, the question whether there is a high level of tertiary accident costs in China is difficult to answer based on the available evidence. In fact, the answer may depend on many factors, including but not limited to, the costs of handling a case in court, the costs of the accident parties in a lawsuit, and the costs of the court itself. However, comprehensive data on detailed administrative costs remain unavailable in China. Nevertheless, the available evidence seems to suggest that most of the traffic compensation claims (nearly 88 percent) are settled out of court and the costs of handling a case are relatively low. Given this evidence, the tertiary accident costs might be relatively low in China. However, we should not ignore the fact that the Chinese victims have poor access to courts, ${ }^{56}$ mainly because the court itself can decide whether the case can be taken or not. Therefore, even though the tertiary accident costs might be relatively low, the primary and secondary accident costs seem to be sufficiently high. In other words, taking the primary, secondary, and tertiary accident costs together, neither the combination of tort and regulation nor the compensation toolbox used in the case of traffic accidents can be considered as effective in China.

\subsection{Answers to Question 5 and Policy Recommendations}

Question 5: To what extent can the law and economics theory be a source of inspiration to China and how can we improve the road traffic accident prevention and compensation systems in China according to the economic benchmarks?

Following the critical analysis sketched in section 1.4, this section attempts to provide some suggestions regarding what China should do to improve the current legal frameworks for both traffic accident prevention and compensation. However, it should be noted that the recommendations made here are mainly from one perspective (or one view of the cathedral), ${ }^{57}$ being the economic analysis. Moreover, in order to be clear about how these recommendations should be implemented in practice, a distinction is made between the improvements that should be made to China's existing legislation (within both short- and long-term) and the changes that should be made to China's culture and social norms.

\subsubsection{Recommendations for China's Legislation}

Ideally, there are a number of strategic and specific issues that could be changed by Chinese legislators. In other words, in an ideal world, Chinese legislators could take the following steps to make the current RTA prevention and compensation systems perform their functions more efficiently.

Firstly, several changes should be made in the CVLI sector. To begin with, Chinese legislators should take a number of steps to promote competition in the insurance market. For insurance, they could revise competition and insurance laws, encouraging new insurers to enter.

\footnotetext{
${ }^{56}$ For example, there are substantial barriers to justice in environmental cases in China. See Van Rooij (2010, pp. 55-77); Wainwright, Wu, and Van Rooij (2012, pp. 106-124).

${ }^{57}$ The phrase is used by Calabresi \& Melamed (1972, pp. 1089-1128) to refer to the fact that they may neglect some points, because to understand the Cathedral one must see all of them.
} 
Moreover, Chinese legislators should ensure that the duty to insure is sufficiently enforced among motor vehicle drivers, especially motorcycle and tractor drivers. Thirdly, they should guarantee that a victim can directly claim against the liability insurer for insurance payments. Fourthly, Chinese legislators should also guarantee that they will not impose strict restrictions on the insurer's ability to do risk-differentiation, especially in the case of CVLI. In this sense, premiums of the CVLI should be less regulated and more risk differentiated, rather than just based on the size and loading capacity of the motor vehicles. Moreover, the Bonus-Malus system should be further refined. Surcharges and discounts in the premiums should be linked with both the frequency and the severity of the accidents. Also, the Bonus-Malus system should be more specific (i.e. dividing drivers into more risk categories) and needs to be extended to motorcycles and tractors. Last but probably most importantly, coverage under the CVLI should be increased to guarantee a sufficient level of compensation to traffic victims, and should be linked with the insured's degree of fault.

Moreover, due to the prevalence of the judgment-proof problem, China should, at least for the short term, control road traffic accidents by relying more on regulations and less on liability law. On the one hand, police forces should guarantee sufficient enforcement of regulation among all road users, especially among non-motor vehicle users (i.e. electric bike riders, cyclists, and pedestrians). On the other hand, regulations and laws related to road traffic accidents should rely more on clearly-defined rules rather than on vaguely-worded principles. To be more specific, firstly, regulations governing road-users' behaviour should be clear and most importantly be accompanied by clear, mandatory sanctions for noncompliance. Secondly, goals of tort law and rules on how to establish liability, such as the rules for determining fault ${ }^{58}$ and causation, need to be further clarified, in order to reduce fraud and corruption issues in court. Thirdly, when it comes to rules that are used to calculate tort damages, the current objective estimates developed by the TLL and the SPC Interpretation on $\mathrm{PI}^{59}$, particularly those used to compute the value of death and disability, should be modified, taking into account the average life expectancy in China. Moreover, local courts should not impose any arbitrary caps on the compensation for pain and suffering. Alternatively, pain and suffering damages would be better if ignored or roughly estimated (i.e. using simple tables or formulas) when they are relatively small, but be carefully calculated when they are substantial. Note that even though Chinese injurers should bear the cost of the accidents they cause, the liability for an accident in China, as well as the standards of care and the amounts of damages awarded, could be lower than those in developed countries. Equally importantly, the clearly-defined regulatory rules and the standardized rates of compensation may face the risk of lagging a long way behind changes in the economy. To avoid this side effect, a panel of experts (i.e. experts on traffic, judges, insurance companies) should review the numbers and update them regularly.

Lastly, the interplay between regulation and liability needs to be clear: violation of regulatory rules/standards would be better if considered as fault automatically, whereas compliance with regulatory rules/standards cannot act as an excuse to escape liability. Furthermore, in order to stimulate access to courts, China should make it easier for the poor traffic victims to pursue their civil rights (via either legal aid or contingency fees).

\footnotetext{
${ }^{58}$ See art. 6 of the TLL and art. 76 of the RTSL.

${ }^{59}$ See article 16-19 of the TLL and article 17-30 of the SPC Interpretation of the PI.
} 
Even though the above-listed policy recommendations are really necessary, we do realize that some of them seem unrealistic or even "utopian", at least in the short run. Therefore, it is necessary for us to make a distinction between quick-wins (where the changes are relatively easy to be adopted, have immediate benefits, and can be delivered quickly after the changes begin) and long-term strategies (where changes seem difficult to be launched and step-bystep improvements are needed).

To make it clearer, most of the quick-wins are related to the CVLI sector. ${ }^{60}$ Examples are increasing the coverages, adopting a more refined Bonus-Malus system, extending the BonusMalus system to motorcycles and tractors, and allowing the victim's direction against the insurer. In additional, punishing road users when they commit traffic violations, and calculating tort damages (especially damages for death, disability, and pain and suffering) more carefully, can also be done within a short-period of time. By contrast, some aspects of the current legislation need a long-term to change, such as improving the clarity in road traffic accident laws and regulations, ${ }^{61}$ stimulating competition in the insurance market, removing strict regulation on CVLI premiums, and increasing safety morality among road users via strong enforcement of traffic safety regulation. In fact, enforcement via police forces can only be effective if the road users treat the threat of punishment as a realistic possibility. However, China now has too many traffic offences but too few police. It comes as no surprise that Chinese police forces are faced with enormous burdens to detect and handle road traffic offenders. The heavy burden of work, together with other common issues (i.e. corruption and fraud), hamper the enforcement of traffic safety regulation in China. However, improving the certainty of punishment seems relatively easy to make within a short-period of time, while the other problems (such as the knowledge and training problem, the equipment problem, and the management and organizational problem) need a long-period of time to be fixed (Wegrnan, 1992, pp. 9-12).

\subsubsection{Recommendations for China's Culture and Social Norms}

In addition to improvements to China's current legislation, several changes can also be done to culture and social norms. Firstly, the bias against first-party (victim) insurance (i.e. personal accident insurance and life insurance) is deeply rooted in Chinese culture and cannot be changed overnight. Indeed, increasing public awareness of the benefits of first-party insurance is a long-job. This might, for example, possibly be done by public educational campaigns, advertising, training and communication, all of which are very time and money consuming. People's persistence in some traditional forms of risk-management, namely personal savings and inter-generational care, is another obstacle to the effectiveness of firstparty insurance in China. Such persistence seems unlikely to change in a short period. However, with further economic development, together with deeper urbanization, the

\footnotetext{
${ }^{60}$ Discussion of the development of the CVLI in China also confirmed that changes happen in this sector within a short period of time. See supra. section 5 of Chapter 1 and section 5.1 and 5.2 of Chapter 2 .

${ }^{61}$ As discussed in Chapter 1 and 2, generality and flexibility seem to be the fundamental principles when drafting Chinese legislations. To comply with these principles, Chinese legislations have the tradition of being vaguely worded. From the legislator's point of view, on the one hand, vague legislations are elastic and can be quickly adapted to the changing reality. On the other hand, vague legislations allow the legislator to leave sensitive and controversial issues undecided. See also Blasek (2015, pp. 52-59).
} 
persistence of self-savings and relatives' help might change in the future, thus increasing the need for first-party insurance.

In China, a comprehensive and generous social security scheme is still not feasible at this stage. On the one hand, China is now in the process of building a credible legal system and making its citizens accountable for their own wrongful behaviour. ${ }^{62}$ In this context, relying mainly on the social security schemes to provide compensation is unlikely to be welcomed by Chinese legislators and citizens. On the other hand, in China, it seems extremely difficult to improve the poor and unemployed citizen's access to social insurance in particular. Admittedly, extending social security schemes and increasing social security coverages requires a lot of effort on the government's side. These efforts may include improving tax collection, creating new agencies to cover currently excluded groups, financing these new programs through general taxation, reducing the costs of formal-sector benefits, and increasing the costs of informal-sector benefits (Dethier, 2007). Not surprisingly, pursuing each of these efforts requires huge government spending and strong government institutional capacity, both of which seem impossible to be achieved in a short run. However, in the future with stronger economic development and government capacity, social security schemes may become more available to victims in China. Consequently, the incentives for the victims to use tort law to obtain compensation may be largely weakened.

\section{Academic Contributions}

This research summarizes the available law and economics models and applies them to analyze problems in China. ${ }^{63}$ By doing so, this research offers a view of the academic debates about two questions. Firstly, what could accident laws do to bring down the high rates of road traffic accidents in China? Secondly, what are the real effects of different traffic accident prevention and compensation instruments in China? With regard to the latter, this research, via applying the economic analysis, identifies effects that Chinese legislators and legal scholars are not familiar with and do not consider as obvious. For example, the Chinese legislators and legal scholars should ask themselves, had they realized that uncertainty surrounding the determination of negligence may systematically lead to over-deterrence? Had they ever focused on the advantages of strict liability over the negligence rule in controlling driving frequency and in extending insurance to uninsured accident victims? Had they recognized that individuals are unlikely to insure against many non-pecuniary losses? Had they appreciated that great accuracy in subjective assessment of tort damages ex post cannot influence the accident party's ex ante behaviour? Were they aware of the argument that the introduction of compulsory liability insurance is unlikely to be socially beneficial if the insurer's capacity to differentiate risks is strictly limited and if the insurance market is highly-concentrated? After reflecting on these questions in this research, I believe the reader can get an enhanced understanding on how liability, insurance and other preventive and compensatory systems works.

\footnotetext{
62 In the early years, when the Chinese economy was still heavily socialist, the injurer's work unit rather than the injurer herself were often made accountable for the injurer's tortious act. However, with the emergence of the market-oriented economy, the work unit's role in victim compensation has gradually vanished. See supra. section 3.2.2 of Chapter 1 and section 5.3 of Chapter 2 .

${ }^{63}$ The value of the economic analysis of accident law was discussed in one of Shavell's remarkable pieces. See Shavell (1987, pp. 291-298).
} 
Admittedly, the law and economics analysis, a movement developed mainly in the US, cannot explain all possible developments in China. For example, from a law and economics perspective, it is difficult to understand why China, on the basis of insolvency, introduced the compulsory liability insurance scheme for motor vehicles, and why the coverage in such schemes is very limited. Also, from an economic perspective, the drivers (the potential injurers) who are afraid of being harmed by traffic accidents should prefer first-party insurance rather than liability insurance. But this seems not to be the case in China and is difficult to be explained. Moreover, the economic analysis suggested that the injured party should have a right to directly claim against the liability insurer. However, the direct action is allowed under OVLI but is total excluded under the CVLI, the reasons for which are not apparent. Likewise, it's not easy to explain why accidents caused by the third party cannot be covered by the social security schemes and why poor victims have to obtain social security benefits upon request in China. From an economic perspective, social security schemes are expected to place fewer barriers for victims to receive compensation. Thus, there are a variety of factors (i.e. history, legal culture, power of interest groups, and opinions of influential jurists and commentators) that go beyond the ones provided in the law and economics literature that shape the law. In this respect, the inconsistency between the observed legal rules and the theoretical optimal can, to some extent, provide insights to improve the current economic models. As some authors argue, "if law and economics wants to increase its explanation power, it cannot remain US-centric, but must widen its horizons to include other legal systems and the dynamics of transnational exchanges and influences" (Caterina, 2006, pp. 166-167).

Limitations of the Research and Possibilities for Future Research

This research has provided a description of the legal instruments used in China regarding both road traffic accident prevention and victim compensation. After the descriptive and explanatory introduction, the effectiveness of these instruments has been evaluated critically from an economic perspective and some normative questions have been addressed. Even so, this research still shows certain limits and need to be improved from the following aspects.

Firstly, when studying the compensatory role played by the Chinese tort law, only the US is selected for a comparison, mainly because both countries use the tort system for meeting victim's basic needs in traffic accidents. Most European legal systems are not included in the comparative study, as they all have well-developed social security schemes and the role played by the tort system in providing compensation to traffic victims is rather modest. However, due to the financial shortfall in recent years, the governments in many European countries tended to reduce social security payments. Therefore, it is reasonable to expect that the need for victims to use tort law to receive compensation of basic needs may increase in the European context in the next few years. If this is the case, the tort system of some European countries will have to be studied and compared. Moreover, besides China and the US, there are some developing countries, where tort law is also primarily used to provide compensation to accident victims. Furthermore, the CVLI scheme in China, Japan ${ }^{64}$ and

\footnotetext{
${ }^{64}$ Similar to China, in Japan, the insurance payments offered by the CVLI are also relatively limited, accounting for 69 percent of the total compensation paid to automobile accident victims. The automobile accident compensation system in Japan has been discussed thoroughly by Tanase (1990, pp. 651-692). Moreover, similar to China, the automobile insurance industry in Japan has also been strictly regulated by the government. See
} 
Taiwan ${ }^{65}$ seems to show great similarities in terms of both insurance payments and its interplay with tort. This calls for further research on whether these regions face the same obstacles in providing compensation to traffic victims through CVLI or tort, and whether the policy recommendations made in this study can be extended to those countries.

Secondly, this research mainly focuses on two goals: accident prevention (deterrence) and victim compensation. However, traffic liability rules, or generally the tort liability system within one country may aim at other goals, such as corrective and distributive justice, fairness, equal treatment, punishment, and promoting social harmony (Koziol, 2017, pp. 75-85). Moreover, these aims may even change over time. The ignorance of those aims might be dangerous, ${ }^{66}$ since some liability rules (i.e. equitable liability, $10 \%$ rule in China) are difficult to justify in the view of deterrence or compensation, but these rules can be used to achieve other tort law aims. Even though focusing only on the goals of deterrence and compensation is difficult to justify from a legal perspective, it is in line with the economic analysis. ${ }^{67}$

Thirdly, improving safety on the road is a very complex task that cannot be solely accomplished by legal instruments, like regulation and tort liability. Other non-legal measures, including launching an education campaign on traffic safety, eliminating defects of vehicles, ameliorating road and traffic engineering designs can also have important roles to play. Therefore, in future research, attention should also be paid to these non-legal instruments and try to elaborate how these non-legal instruments could go hand-in-hand with liability and regulation to bring down the frequency of road traffic accidents.

Fourthly, this research analyzed the status quo in China from the economic perspective and some empirics regarding the effectiveness of the relevant legal instruments. However, more empirical evidence is required not only to make the analysis more accurate but also for assessing efficiency. Unfortunately, most empirical data is either confidential or not available in China at this moment. Without comprehensive data, this research cannot sufficiently address, for instance, whether tort law or regulation in China really has a deterrent effect in road traffic accident cases. Does the Chinese traffic liability system compensate poorly and costly? Do problems of moral hazard and adverse selection really exist in the Chinese CVLI market? Is the Bonus-Malus system with the CVLI able to control the moral hazard risk efficiently? All these questions deserve to be carefully examined if relevant empirical data becomes available in the future.

Fifthly, the main conclusions of this research are built upon economic observations. However, these observations are somewhat speculative, given the numerous assumptions involved. For

\footnotetext{
Hayakawa, Fischbeck, and Fischhoff (2000, pp. 385-403). See also General Rating Insurance Company of Japan (2016, pp. 1-56).

${ }^{65}$ The same as China, the compulsory automobile liability insurance (CALI) in Taiwan is also aimed at compensating the basic loss of the victims in traffic accidents. The introduction of the CALI in Taiwan can be found at http://www.cali.org.tw/en/.

${ }^{66}$ Solely looking at the aim of deterrence might also be very dangerous, see Koziol (2017, pp. 75-85).

${ }^{67}$ Some scholars argued that the aims of tort law are probably one of the domains where the differences between the legal and economic approaches are the greatest. See for examle Schwartz (1996, pp. 1801-1834). In fact, since the 1990s some scholrs have attempted to reconcile these two approaches. For a summary of this reconciliation, see Faure (2017, pp. 79-113).

${ }^{67}$ See an overview of the literature on behavioural law and $e$
} 
example, all parties are assumed to have information about the applicable liability regime, the probability and the magnitude of the accident. Moreover, these parties are equally assumed to have the ability to process this information correctly and adapt their behaviour accordingly, thereby reducing accident risks in an efficient manner. These rationality assumptions have been criticized by behavioural economists. According to them, information deficiencies often exist, and individuals sometimes suffer cognitive bias (i.e. the probability neglect, availability heuristic and over-optimism). ${ }^{68}$ All these problems apparently affect the way in which the accident parties behave and ultimately affect the achievement of the optimal deterrence. In this case, the arguments provided by behavioural law and economics should be taken into account in future research. ${ }^{69}$

Lastly, this research does not discuss some innovation developments (i.e. ride-sharing and autonomous driving technology) that may affect the shaping of road safety laws, regulations, as well as the pricing of automobile insurance. ${ }^{70}$ For example, by reducing human errors (which are the cause of most traffic collisions), autonomous driving technologies will substantially lower the number of traffic accidents. Consequently, the costs of related automobile insurance will be largely reduced. Secondly, autonomous driving technologies may also greatly reduce the category of accidents for which there is a human being to blame. Since accidents involving autonomous cars might be caused simply by software failures rather than by human errors, liability will be shifted from the driver to the manufacturer. Therefore, the future litigation might focus more on car makers or designers and less on vehicle drivers. ${ }^{71}$ Lastly, autonomous-car technologies may also change the seriousness of traffic accidents. Taking into account all these changes that are brought by autonomous driving, questions, such as how to price insurance premiums for autonomous-cars, how to regulate liability for accidents caused by such cars, should be studied in the future. When it comes to ride-sharing, this new innovative service is believed to have the potential to reduce traffic, ${ }^{72}$ promote the efficient use of vehicles, ${ }^{73}$ and relieve the burden on public transport. Also, when driving more frequently than before, ride-sharing drivers' driving skill might be improved, which in turn might improve traffic safety. However, on the other hand, share-driving will result in more injuries than solo driving when a traffic collision occurs. In addition, ride-sharing drivers will drive more frequently and will be more fatigued while driving, thus increasing their

\footnotetext{
${ }^{68}$ See an overview of the literature on behavioural law and economics is provided by Ogus (2006) and Faure (2010, pp. 11-68).

${ }^{69}$ However, some authors argue that behavioural law and economics may not provide a solid theoretical basis for policy implementation, because the results of the behavioural economics are often very case-specific, context-dependent and often point in different directions. See Faure (2017, pp. 89-91).

${ }^{70}$ In China, as the sharing economy expands, ride-sharing becomes more and more popular in China. Recent data shows that more than 10 million private drivers have been enrolled in the ride-sharing industry in China, serving about 400 million registered app users. See He (2016). However, the existing regulatory framework seem to has some problems. See Zou (2017, pp. 272-289).

${ }^{71}$ Some authors argue that since the left-over traffic accidents are the ones for which there is no at-fault driver, no-fault compensation schemes may be attractive. See Anderson, Heaton, and Carroll (2010, pp. 135-144).

${ }^{72}$ For example, when ride-hailing services become increasingly popular, people's incentives to buy automobiles will be decreased thereby reducing environmental harms. Moreover, since fewer cars are running on the road, fewer parking spaces will be needed, saving more space for other uses. The benefits of ride-sharing have been discussed in detail by Brishen Rogers, see (Rogers, 2015, pp. 90-101).

${ }^{73}$ The various forms of efficiencies that uberization platforms provide have been discussed thoroughly by Edelman and Geradin. See Edelman and Geradin (2016, pp. 296-305).
} 
chances of being involved in a car accident. ${ }^{74}$ Taking all these facts together, it is difficult to say whether ride-sharing will improve road safety. Therefore, more studies need to be done in the future. Ride-sharing may also result in some insurance gaps, especially if a traffic collision occurs within the period when a ride-sharing driver is hoping for a passenger but does not yet have a specific ride request. ${ }^{75}$ As a result of such insurance gaps, injured parties may be left unprotected without any insurance coverage. In such cases, how to protect injured parties deserves future attention.

\section{The Way Forward: Towards Improving Traffic Safety in China}

After all the discussions, what can be learned from this dissertation? Firstly, it is clear that the joint use of regulation and tort liability in China does not function effectively in preventing traffic accidents and in promoting traffic safety. It is also clear that the toolbox used to compensate traffic accident victims is relatively under-developed in China. However, these problems should not have happened in today's China. Even though China is still a developing country in terms of GDP per capital, China is already the world's second largest economy with strong economic power. In such an economic situation, the government should have done more and spent more to improve traffic safety, and people in China are expected to receive a high level of compensation when they are involved in road traffic accidents. However, our analyses found just the opposite results. When a road traffic accident happens, the insolvency risk is still high; the victim is still poorly compensated; and effective or efficient loss-spreading through compensatory schemes is still not feasible in today's China. All these problems do not fit in China's current economic situation and thus should not happen at the current phase. Moreover, all of the-above listed deficiencies may be one of the reasons why the situation of Chinese victims is still "miserable", even though the number of road traffic accidents has already significantly decreased.

By using the economic analysis, this dissertation has shown that the current situation of traffic accident victims and traffic safety are problematic and should be changed, inter alia, by doing the following. To reiterate briefly:

- Safety regulation should be strongly enforced, especially among non-motor vehicles, to produce sufficient deterrence. This could be achieved, for example, by imposing small punishments with a high rate of detection and by paying more attention to regulate nonmotor vehicle parties' behaviour;

- liability rules and regulatory standards should be more clear, in order to avoid uncertainties and to make corruption and fraud issues difficult to hide;

- caps on tort damages, especially arbitrary caps on non-pecuniary damages (i.e. compensation for death, disability, and pain and suffering) should be removed. Tort losses should be more carefully calculated and the assessment of the losses should be correct on average.

\footnotetext{
${ }^{74}$ One study argues that ride-sharing may result in a growth rather than a decline in the overall amount of kilometers driven in cities, because people are still taking the same number of trips, even if they share cars with others (Clewlow \& Mishra, 2017, pp. 1-35).

75 There are other potential problems with ride-sharing companies' insurance coverage, even after the ridesharing drivers accept the ride request. See Davis (2015, pp. 1097-1142).
} 
- the insolvency risk of tortfeasors needs to be further eliminated. This could be done, for instance, by increasing the CVLI coverages (short-term strategy) or by improving social security benefits (long-term strategy);

- moreover, to function more effectively, the CVLI also needs to be improved in the following ways. First of all, competition in the insurance market needs to be promoted. In the meantime, the current restrictions on the CVLI insurer's ability to do risk-differentiation need to be removed. This means that the duty to insure needs to be sufficiently enforced, particularly among motorcycles and tractors; the premiums should be more risk-based and coverage should be linked with the insured's degree of fault; the Bonus-Malus system should be further refined and be applied to all types of motor vehicles; and the victim should be entitled to have the right to bring a direct action against the CVLI insurer;

- the collateral benefits set-off rule (deduction), and subrogation of the insurer or provider should be allowed, if the victim received compensation from multiple sources;

- accident parties should be entitled to claim social security benefits even if the accident was caused by a third party. And, to function effectively and to complement the traffic liability system well, social security benefits should be paid rapidly without regard to fault and without filing any application for benefits.

Could the situation in China really be improved after taking all these aspects into consideration? We hope so, but we also aware that there are other issues to be addressed as well. For example, improving road design and regulatory measures, promoting moral and national education on traffic safety, and developing better techniques to help prevent car crashes and keep drivers safe. However, this dissertation did not discuss these issues and was limited to examining liability rules and compensation schemes that are already there. Even so, we still hope this dissertation could contribute to a better level of traffic accident prevention, a lower level of traffic fatalities, and a better level of compensation to victims of road traffic accidents in China. 